\title{
Papers
}

\section{Birth weight, childhood socioeconomic environment, and cognitive development in the 1958 British birth cohort study}

Barbara J M H Jefferis, Chris Power, Clyde Hertzman

\begin{abstract}
Objectives To examine the combined effect of social class and weight at birth on cognitive trajectories during school age and the associations between birth weight and educational outcomes through to 33 years. Design Longitudinal, population based, birth cohort study.

Participants 10845 males and females born during 3-9 March 1958 with information on birth weight, social class, and cognitive tests.

Main outcome measures Reading, maths, draw a man, copying designs, verbal and non-verbal ability tests at ages 7,11 , and 16, highest qualifications achieved by 33 , and trajectories of maths standardised scores at 7-16 years.

Results The outcome of all childhood cognitive tests and educational achievements improved significantly with increasing birth weight. Analysis of maths scores at 7 and of highest qualifications achieved by 33 showed that the relations were robust to adjustment for potential confounding factors. For each kilogram increase in birth weight, maths z score increased by 0.17 (adjusted estimate $0.15,95 \%$ confidence interval 0.10 to 0.21$)$ for males and $0.21(0.20,0.14$ to 0.25$)$ for females. Trajectories of maths z scores between 7 and 16 years diverged for different social class groups: participants from classes I and II increased their relative position on the score with increasing age, whereas classes IV and V showed a relative decline with increasing age. Birth weight explained much less of the variation in cognition than did social class (range $0.5-1.5 \%$ v 2.9-12.5\%).

Conclusions The postnatal environment has an overwhelming influence on cognitive function through to early adulthood, but these strong effects do not explain the weaker but independent association with birth weight.
\end{abstract}

\section{Introduction}

A consistent association between weight at birth and cognitive development has been established within cohorts born during different periods in the 20th century. ${ }^{1-4}$ Earlier studies that focused on low birth weight or small for gestational age infants showed an increased incidence of neurological deficits or poorer cognitive skills through childhood compared with counterparts of normal weight. ${ }^{5-9}$ The association between weight at birth and later cognition persists across the whole spectrum of birth weight, rather than being confined to an extreme group and is not explained by confounding or effect modification by social factors. ${ }^{1-4} 10$

Most studies have investigated cognition at one age only. ${ }^{13}{ }^{1011}$ A study of sibship pairs found an increasing intelligence quotient at age 7 from 1500 to $3999 \mathrm{~g}$ birth weight. ${ }^{4}$ In a Scottish sample, cognitive function at 11 years was related retrospectively to birth weight, and in a Danish cohort of male conscripts aged up to 20, cognitive function increased across the range of birth weights up to $4.5 \mathrm{~kg}^{13}$ One study that has assessed cognitive function at several ages is the 1946 British birth cohort. ${ }^{2}$ In this study birth weight was related to verbal and non-verbal intelligence, word pronunciation, and vocabulary at age 8 , and differences persisted through ages 11,15 , and $26 .{ }^{2}$

Socioeconomic background also has a strong influence on cognitive function in children, which perhaps exceeds the impact of birth weight. ${ }^{1}$ Yet few studies have constructed cognitive trajectories through childhood and adolescence from which the combined contributions of birth weight and social environment can be assessed. Such analyses are required to establish whether effects of birth weight and social environment persist with increasing age.

We aimed to examine the combined effect of birth weight and socioeconomic environment on cognitive trajectories during childhood. We investigated the influence of birth weight on seven measures of cognitive and educational outcomes at 7, 11, 16, and 33 years in the 1958 British birth cohort. ${ }^{12}$

\section{Methods}

Sample

The 1958 birth cohort comprises individuals born during 3-9 March 1958 in England, Scotland, and Wales. ${ }^{12}{ }^{13}$ The cohort was followed at ages $7,11,16,23$, and 33. During the first three follow ups, response rates were $91 \%, 91 \%$, and $87 \%{ }^{14}$ The sample we studied comprises singletons (we excluded 390 multiple births) with information on birth weight and a gestational age between 32 and 44 weeks ( $\mathrm{n}=13$ 980). We excluded

\author{
Institute of Child \\ Health, Centre for \\ Paediatric \\ Epidemiology and \\ Biostatistics, \\ London \\ WC1N 1EH \\ Barbara J M H \\ Jefferis \\ research fellow \\ Chris Power \\ professor \\ Department of \\ Health Care and \\ Epidemiology, \\ Faculty of Medicine, \\ University of British \\ Columbia, \\ Vancouver, BC, \\ Canada V6T 1Z3 \\ Clyde Hertzman \\ professor \\ Correspondence to: \\ C Power \\ C.Power@ich. \\ ucl.ac.uk \\ bmj.com 2002;325:305
}


babies born to unmarried women $(\mathrm{n}=2843)$ because gestational age was not recorded. Our multivariate analyses are based on 10845 participants with data on birth weight, gestational age, maths scores at 7 years, and potential confounding factors. This sample has a similar mean birth weight (3434 g males, $3300 \mathrm{~g}$ females) to that of the sample ( $\mathrm{n}=13 \mathrm{980})$ with relevant data (3425 g males, $3290 \mathrm{~g}$ females). With further attrition to age 33 , the sample with data on educational qualifications $(n=9300)$ has a similar mean birth weight (males $3435 \mathrm{~g}$, females $3289 \mathrm{~g}$ ) to the 13980 participants. For social class at birth, 23.9\% (1945/ $8145)$ of males and $24.6 \%(1890 / 7688)$ of females from the original birth sample were from classes IV and $\mathrm{V}$ or single households, compared with $22.2 \%$ $(1232 / 5561)$ and $22.6 \%(1196 / 5284)$, respectively, in the multivariate sample.

\section{Measures}

School tests

At 7, 11, and 16, the participants took age appropriate tests at school for maths, reading, general ability, and perceptual and motor skills. The tests were conducted over several months. Arithmetic at age 7 comprised 10 problems with graded levels of difficulty (range 0-10); when necessary teachers read the questions to poor readers. At age 11 the mathematics test was constructed by the National Foundation for Educational Research in England and Wales (range 0-40). For the survey at 16 years a mathematics comprehension test (range 0-31) was constructed at Manchester University. The Southgate test was used to detect poor readers at age $7^{15}$ : children selected from several words the one corresponding to a picture; teachers also read out words that the children identified from a list. Reading tests at ages 11 and 16 were parallel to the Watts Vernon comprehension test. Tests of perceptual and motor ability included the Goodenough draw a man test at age 7 and the copying designs test at age $11 .^{16}$ The latter presented children with six designs: circle, square, triangle, diamond, cross, and star, which they copied twice. A general ability test at age 11 approximated the conventional intelligence test, with verbal and non-verbal components. ${ }^{17}$ Highest qualifications achieved by age 33 were categorised as no qualifications, less than $\mathrm{O}$ level (or equivalent), $\mathrm{O}$ level (or equivalent), A level (or equivalent), or higher qualification.

\section{Birth weight and gestational age}

Birth weight was recorded in pounds and ounces and converted into kilograms. ${ }^{12}$ Duration of gestation was estimated from the date of the last menstrual period reported by the mother and checked against general practitioner records. The $\mathrm{z}$ (standard deviation) scores of birth weight for gestational age were calculated by sex for each week of gestation.

\section{Social class}

Social position at birth was based on the father's occupation in 1958, classified according to the registrar general's scale, ranging from class I (professional) to $\mathrm{V}$ (unskilled manual). Groups I and II were combined, as were groups IV and $\mathrm{V}$, to give larger numbers in the extreme groups. Households with no male head of household were included with group IV and V.
Confounders

Potential confounders were identified from previous work on cognition, including maternal age, breast feeding, parental education, and parity. Maternal and paternal education were coded according to whether or not they had stayed in school beyond minimum school leaving age (14 years until 1948, 15 years thereafter). Infant feeding was recorded as ever breast fed, and parity was recorded as 0,1 , or $>1$. Maternal age was recorded at the birth of the cohort member as age at last birthday.

\section{Data analysis}

Our initial data analysis examined univariate relations between birth weight and educational outcomes. For tests for linear trend we used analysis of variance across categories of birth weight: $\leqslant 2500 \mathrm{~g}, 2501-3000 \mathrm{~g}$, $3001-3500$ g, 3501-4000 g, $>4000$ g. For parallel analyses we used five categories of standardised birth weight for gestational age.

At age 7 most children scored high marks on the reading test resulting in a highly skewed distribution, whereas at ages 11 and 16 the tests discriminated a range of abilities. Different tests were used for maths at 7 , 11 , and 16 years, so the scales differ for each age, but the distributions are about normal. Given the better discrimination of ability with maths tests, we conducted further analyses with these data and present only simple comparisons for reading scores. We calculated z scores from the raw maths scores for both sexes combined to allow comparisons across the three test ages $(7,11,16)$. The mean score at each age was set to zero, and the standard deviation was set to one. Thus, a child with a $\mathrm{z}$ score of 0 at each age had an average score on each occasion relative to others. An increasing z score with age signalled improvement in relative achievement.

We used linear regression to examine whether the effect of birth weight (continuous variable) on maths at 7 years was robust to adjustment for gestational age and potential confounding factors: maternal age, social class at birth, parity, breast feeding, and parental education. We tested for interactions of birth weight with these confounding factors plus sex. We repeated the analyses after excluding participants with a handicap or disability during childhood $(n=515)$ and births at 37 or less weeks gestation $(n=1132)$. Linear regression models provide estimates separately for ages 7,11 , and 16 of the percentage of variance explained by birth weight and class at birth. We repeated the linear regression analyses with highest qualifications achieved by 33 years as a continuous outcome.

We plotted trajectories of $\mathrm{z}$ score for maths from age 7 to 16 according to birth weight and class at birth, and we used a repeated measures multilevel model for the longitudinal analysis. ${ }^{18}$ The model takes into account the nesting of repeated maths scores within individuals. We used age of test (to the nearest month) in the models, and data are centred on age 7 . We tested interactions between birth weight and social class, age and social class, and age and birth weight.

\section{Results}

All cognitive tests and educational achievements differed across birth weight categories from ages 7 to 33 (table 1). For both sexes there was a significant trend 
Table 1 Mean educational scores at ages 7, 11, and 16 years in 6242 males and 5912 females and adult qualifications at age 33 (percentages) according to birth weight

\begin{tabular}{|c|c|c|c|c|c|c|c|c|}
\hline \multirow[b]{2}{*}{ Tests or qualifications } & \multicolumn{6}{|c|}{ Birth weight (g) } & \multirow[b]{2}{*}{ Mean } & \multirow[b]{2}{*}{$P$ for trend } \\
\hline & No & $<2500$ & $2501-3000$ & $3001-3500$ & $3501-4000$ & $>4000$ & & \\
\hline Males & & $(n=232)$ & $(\mathrm{n}=957)$ & $(n=2202)$ & $(n=2073)$ & $(n=752)$ & & \\
\hline \multicolumn{9}{|l|}{ Maths: } \\
\hline Age 7 & 6216 & 4.8 & 4.9 & 5.3 & 5.5 & 5.5 & 5.3 & $<0.001$ \\
\hline Age 11 & 5820 & 14.4 & 15.2 & 17.0 & 18.2 & 18.9 & 17.3 & $<0.001$ \\
\hline Age 16 & 4854 & 11.8 & 12.1 & 13.7 & 14.3 & 14.1 & 13.6 & $<0.001$ \\
\hline \multicolumn{9}{|l|}{ Reading: } \\
\hline Age 7 & 6242 & 20.9 & 21.8 & 22.8 & 23.2 & 23.3 & 22.8 & $<0.001$ \\
\hline Age 11 & 5822 & 14.3 & 15.3 & 16.2 & 16.6 & 17.1 & 16.3 & $<0.001$ \\
\hline Age 16 & 4871 & 23.3 & 24.5 & 25.9 & 26.4 & 26.2 & 25.8 & $<0.001$ \\
\hline Draw a man* & 6138 & 22.0 & 23.1 & 23.5 & 24.3 & 24.0 & 23.7 & $<0.001$ \\
\hline Copying designs $\dagger$ & 5814 & 8.0 & 8.2 & 8.4 & 8.4 & 8.5 & 8.4 & $<0.001$ \\
\hline Verbal ability $\dagger$ & 5822 & 19.0 & 20.2 & 21.3 & 22.0 & 22.5 & 21.5 & $<0.001$ \\
\hline Non-verbal ability† & 5822 & 18.8 & 20.2 & 21.0 & 21.6 & 21.8 & 21.1 & $<0.001$ \\
\hline Adult qualifications: & & & & & & & & $<0.001$ \\
\hline None & 364 & 9.7 & 10.6 & 8.0 & 7.9 & 6.6 & 8.2 & \\
\hline$<0$ level & 578 & 15.2 & 14.2 & 13.9 & 11.7 & 12.6 & 13.1 & \\
\hline 0 level & 1050 & 27.9 & 26.7 & 23.8 & 23.3 & 20.5 & 23.8 & \\
\hline A level & 1104 & 21.8 & 24.2 & 25.6 & 24.6 & 26.5 & 25.0 & \\
\hline Higher & 1317 & 25.5 & 24.3 & 28.8 & 32.4 & 33.8 & 29.8 & \\
\hline Females & & $(n=289)$ & $(n=1258)$ & $(n=2402)$ & $(n=1526)$ & $(n=433)$ & & \\
\hline \multicolumn{9}{|l|}{ Maths: } \\
\hline Age 7 & 5908 & 4.3 & 4.8 & 5.1 & 5.3 & 5.4 & 5.1 & $<0.001$ \\
\hline Age 11 & 5529 & 12.8 & 15.8 & 16.9 & 18.4 & 17.8 & 16.9 & $<0.001$ \\
\hline Age 16 & 4653 & 9.8 & 11.8 & 12.2 & 12.9 & 13.2 & 12.3 & $<0.001$ \\
\hline \multicolumn{9}{|l|}{ Reading: } \\
\hline Age 7 & 5912 & 22.2 & 23.9 & 24.7 & 25.2 & 25.3 & 24.6 & $<0.001$ \\
\hline Age 11 & 5531 & 14.1 & 15.8 & 16.3 & 17.0 & 16.8 & 16.3 & $<0.001$ \\
\hline Age 16 & 4679 & 22.9 & 25.1 & 25.6 & 26.5 & 26.0 & 25.6 & $<0.001$ \\
\hline Draw a man* & 5806 & 22.2 & 23.6 & 24.4 & 24.4 & 25.6 & 24.2 & $<0.001$ \\
\hline Copying designs† & 5516 & 8.1 & 8.2 & 8.3 & 8.4 & 8.6 & 8.3 & $<0.001$ \\
\hline Verbal ability $\dagger$ & 5533 & 20.2 & 22.6 & 23.7 & 24.7 & 24.1 & 23.6 & $<0.001$ \\
\hline Non-verbal ability $\dagger$ & 5533 & 18.5 & 20.7 & 21.4 & 22.3 & 22.1 & 21.4 & $<0.001$ \\
\hline Adult qualifications: & & & & & & & & $<0.001$ \\
\hline None & 452 & 17.7 & 10.0 & 9.6 & 8.2 & 10.2 & 9.8 & \\
\hline$<0$ level & 790 & 22.8 & 19.8 & 16.9 & 13.9 & 17.5 & 17.1 & \\
\hline 0 level & 1671 & 37.1 & 36.5 & 35.2 & 38.8 & 31.8 & 36.2 & \\
\hline A level & 492 & 5.5 & 10.9 & 11.2 & 10.0 & 12.5 & 10.7 & \\
\hline Higher & 1206 & 16.9 & 22.8 & 27.1 & 29.0 & 28.0 & 26.2 & \\
\hline
\end{tabular}

Multiple births ( $n=390$ ) excluded, gestational age within range 32 to 44 weeks.

${ }^{*}$ Age 7.

†Age 11.

of increasing mean scores with increasing birth weight In general there was an increase in scores or qualifications for each birth weight category-for example, the proportion of men with higher qualifications increased from $26 \%$ in the lowest $(\leqslant 2500 \mathrm{~g}$ ) birth weight group to $34 \%$ in the highest $(>4000 \mathrm{~g})$. For women equivalent percentages were $17 \%$ and $28 \%$. Standardised maths scores increased with increasing birth weight at all ages: $\mathrm{z}$ scores differed by between 0.23 and 0.48 between the highest and lowest birth weight categories for ages 7 to 16 (table 2). When birth weight was adjusted for gestational age there was a similar increase across categories of increasing birth size for each educational outcome $(\mathrm{P}<0.001$ for linear trend, data not presented).

The relation between birth weight and maths $\mathrm{z}$ scores at 7 years was robust to adjustment for gestational age, maternal age, social class, parity, sex, breast feeding, and parental education (table 3). The score increased by 0.17 and 0.19 respectively for males

Table 2 Mean z scores (95\% confidence intervals) for maths tests at ages 7, 11, and 16 years according to birth weight

\begin{tabular}{|c|c|c|c|c|c|c|}
\hline \multirow[b]{2}{*}{ Age at test } & \multirow[b]{2}{*}{ No } & \multicolumn{5}{|c|}{ Birth weight (g) } \\
\hline & & $<2500$ & $2501-3000$ & $3001-3500$ & $3501-4000$ & $>4000$ \\
\hline \multicolumn{7}{|l|}{ Males: } \\
\hline Age 7 & 6216 & $-0.13(-0.27$ to 0.01$)$ & $-0.08(-0.14$ to -0.01$)$ & $0.07(0.03$ to 0.12$)$ & $0.14(0.10$ to 0.18$)$ & $0.17(0.10$ to 0.24$)$ \\
\hline Age 11 & 5820 & $-0.22(-0.36$ to -0.08$)$ & $-0.14(-0.20$ to -0.07$)$ & $0.04(0.00$ to 0.08$)$ & $0.15(0.11$ to 0.20$)$ & $0.21(0.14$ to 0.29$)$ \\
\hline Age 16 & 4854 & $-0.14(-0.27$ to 0.00$)$ & $-0.10(-0.17$ to -0.03$)$ & 0.13 (0.09 to 0.18$)$ & $0.22(0.17$ to 0.27$)$ & $0.19(0.11$ to 0.27$)$ \\
\hline \multicolumn{7}{|l|}{ Females: } \\
\hline Age 7 & 5908 & $-0.33(-0.44$ to -0.22$)$ & $-0.12(-0.17$ to -0.06$)$ & $-0.01(-0.05$ to 0.03$)$ & $0.08(0.03$ to 0.13$)$ & $0.12(0.03$ to 0.21$)$ \\
\hline Age 11 & 5529 & $-0.37(-0.47$ to -0.27$)$ & $-0.08(-0.13$ to -0.02$)$ & $0.02(-0.02$ to 0.06$)$ & $0.17(0.12$ to 0.22$)$ & 0.11 (0.01 to 0.21$)$ \\
\hline Age 16 & 4653 & $-0.42(-0.53$ to -0.32$)$ & $-0.14(-0.19$ to -0.08$)$ & $-0.07(-0.12$ to -0.03$)$ & $0.03(-0.03$ to 0.08$)$ & $0.06(-0.05$ to 0.17$)$ \\
\hline
\end{tabular}


Table 3 Models of 7 year standardised maths score and highest educational qualifications achieved by 33 years. Values are $\beta$ coefficients ( $95 \%$ confidence intervals) for birth weight $(\mathrm{kg})$ before and after adjustment for confounding factors

\begin{tabular}{|c|c|c|c|c|}
\hline \multirow[b]{2}{*}{ Models } & \multicolumn{2}{|c|}{ Standardised maths scores age 7} & \multicolumn{2}{|c|}{ Highest qualifications age 33} \\
\hline & Males $(\mathrm{n}=5561)$ & Females $(n=5284)$ & Males $(n=3743)$ & Females $(n=3888)$ \\
\hline Birth weight (unadjusted) $^{*}$ & $0.17(0.12$ to 0.22$)$ & $0.19(0.14$ to 0.25$)$ & 0.17 (0.09 to 0.25$)$ & $0.22(0.14$ to 0.30$)$ \\
\hline Plus gestational age & $0.18(0.12$ to 0.23$)$ & $0.21(0.15$ to 0.27$)$ & $0.16(0.07$ to 0.24$)$ & $0.26(0.17$ to 0.34$)$ \\
\hline Plus maternal age & $0.17(0.12$ to 0.23$)$ & $0.20(0.14$ to 0.26$)$ & $0.15(0.07$ to 0.24$)$ & 0.25 (0.16 to 0.33$)$ \\
\hline Plus social class at birth & 0.15 (0.10 to 0.21$)$ & $0.19(0.13$ to 0.25$)$ & $0.11(0.03$ to 0.19$)$ & $0.20(0.12$ to 0.28$)$ \\
\hline Plus parity & 0.16 (0.11 to 0.22$)$ & $0.20(0.15$ to 0.26$)$ & $0.16(0.08$ to 0.24$)$ & $0.28(0.20$ to 0.36$)$ \\
\hline Plus breast feeding & 0.16 (0.11 to 0.22$)$ & $0.20(0.14$ to 0.26$)$ & $0.15(0.07$ to 0.24$)$ & $0.27(0.19$ to 0.35$)$ \\
\hline Plus parental education & 0.15 (0.10 to 0.21$)$ & $0.19(0.14$ to 0.25$)$ & $0.14(0.06$ to 0.22$)$ & $0.26(0.18$ to 0.34$)$ \\
\hline
\end{tabular}

${ }^{*}$ Birth weight $(\mathrm{kg})$ as continuous variable.

and females for each kilogram increase in birth weight. Estimates were little changed after adjustment. Excluding preterm births or participants with disability did not change the relations.

Social background had a strong effect on maths scores, with children from class I and II gaining higher scores than those from class IV and V. The percentage of variance in maths scores explained by class at birth increased from about $3 \%$ at age 7 to $12 \%$ at age 16 , whereas the percentage for birth weight remained at around $1 \%$ (table 4 ).

Participants of low ( $\leqslant 2500 \mathrm{~g}$ ) birth weight from class I and II had higher average $\mathrm{z}$ scores for maths than participants of normal $(>2500 \mathrm{~kg}$ ) birth weight from class IV and V (figure). The maths scores of children of both low and normal birth weight from class I and II showed a relative increase between age 7 and 16 . In class IV and V, however, the scores of participants of normal birth weight showed a relative decline with age. No significant interaction was found between birth weight and social class for maths $\mathrm{z}$ score: a deficit in mean scores is evident for those of low birth weight relative to others in the same class. The figure illustrates the extent to which advantage conferred by higher class applies to individuals of low birth weight, both in initial scores attained at age 7 and in the trajectory through adolescence. On average, by age 16 there was a full standard deviation advantage for children in class I and II, and this advantage was largely shared by those of low birth weight.

The association between maths score and social class seemed to strengthen with age (figure). This was confirmed in a multilevel growth model, showing a significant interaction between class of origin and age: the slope of the maths score trajectories from age 7 to 16

Table 4 Percentage variance explained (adjusted $R^{2}$ ) for linear regression of birth weight and social class at birth on maths $z$ scores at 7,11 , and 16 years and highest adult qualifications at age 33

\begin{tabular}{|c|c|c|c|c|c|}
\hline & \multirow[b]{2}{*}{ No } & \multicolumn{4}{|c|}{ Adjusted $\mathbf{R}^{2}$} \\
\hline & & Birth weight (g) & $P$ value & Social class at birth & $P$ value \\
\hline \multicolumn{6}{|c|}{ Maths scores } \\
\hline \multicolumn{6}{|c|}{ Males: } \\
\hline Age 7 & 6072 & 0.8 & $<0.001$ & 2.9 & $<0.001$ \\
\hline Age 11 & 5690 & 1.4 & $<0.001$ & 9.9 & $<0.001$ \\
\hline Age 16 & 4732 & 1.0 & $<0.001$ & 11.7 & $<0.001$ \\
\hline \multicolumn{6}{|l|}{ Females: } \\
\hline Age 7 & 5784 & 1.0 & $<0.001$ & 2.7 & $<0.001$ \\
\hline Age 11 & 5409 & 1.5 & $<0.001$ & 10.5 & $<0.001$ \\
\hline Age 16 & 4553 & 1.1 & $<0.001$ & 12.5 & $<0.001$ \\
\hline \multicolumn{6}{|c|}{ Adult qualifications } \\
\hline Males & 4307 & 0.5 & $<0.001$ & 9.0 & $<0.001$ \\
\hline Females & 4518 & 0.7 & $<0.001$ & 11.0 & $<0.001$ \\
\hline
\end{tabular}

decreased with less favourable social position. A weaker interaction of birth weight with age became non-significant in a model including the social class interaction with age. An effect of birth weight on the intercept of the growth trajectory for maths scores remained significant after adjustment for all covariates. No interaction was found between social class and birth weight or between sex and birth weight.

In analyses of adult educational level, highest qualifications measured on a 5 point scale increased by 0.17 and 0.22 , respectively, for males and females for each kilogram increase in birth weight (table 3). This effect was robust to adjustment for gestational age, maternal age, social class, parity, sex, breast feeding, and parental education. Excluding preterm births or participants with disability did not change the relations. The percentage variance in adult educational qualifications explained by birth weight ( $<1 \%$ for both sexes) was smaller than social class at birth (9\% for males, $11 \%$ for females) (table 4).

\section{Discussion}

We found an association between birth weight and cognition by using several measures of educational attainment spanning 26 years in the 1958 British birth cohort. The relation held across the normal range of birth weight distribution and persisted with increasing age. The association was evident for both sexes and was not due to confounding by socioeconomic background or parents' education. A strong influence was found of childhood socioeconomic background on cognition,

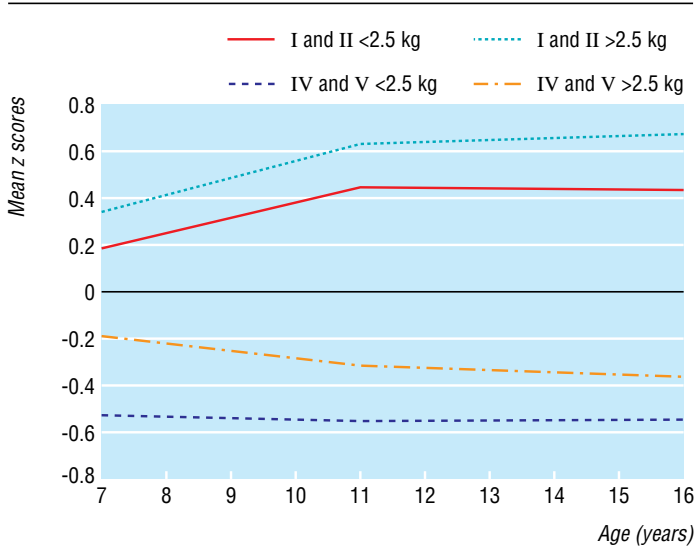

Maths z scores from ages 7-16 years by birth weight and social class at birth (sexes combined). Class IV and V includes individuals with no male heads of household 
which seems to have a greater effect than birth weight at least in respect of maths and highest adult qualifications. Although birth weight and social background had independent effects, these effects seemed to differ over time. Trajectories in maths diverged with increasing age according to social class at birth, but for birth weight the effect remained constant throughout childhood. Social conditions therefore played an increasingly important part in cognitive development. However, we found no evidence that social background modified the effect of birth weight.

\section{Strengths and limitations}

A principal strength of our study is that it uses prospective data from birth onwards in a population based sample that remains broadly representative up to early adulthood. ${ }^{14}$ Our study is unique in investigating the combined effects of birth weight and childhood social background on trajectories in cognitive development into adolescence. It has the benefit of a wide spectrum of cognitive tests and educational outcomes collected over 26 years, whereas most studies examine cognitive function at a single age and therefore cannot assess whether the relation with birth weight changes with age. To our knowledge, we have performed the first population based study examining cognition across the range of birth weight with adjustment for gestational age, thereby providing a better measure of fetal growth than indicated by birth weight alone. Despite associations evident in this sample between birth weight and disability and disability and poor cognitive function, we found that the relation between birth weight and cognitive function does not depend on disability. ${ }^{190}$

Our study has two main limitations. Cognition is notoriously difficult to measure without introducing cultural biases, and this may affect the estimate of the effect of socioeconomic background. However, it is possible that biases are more limited for the maths tests, which depend less on verbal fluency. The highly skewed distribution of the reading tests made it difficult to construct meaningful trajectories of change with time. A further issue concerns the extent to which birth weight and social class at birth are simplifications of complicated processes occurring before and after birth. Increasingly complex statistical models, which include multiple covariates, may reduce the association with birth weight and in so doing deal with the possibility of residual confounding. We cannot discount the possibility that birth weight reflects biological processes in utero that independently affect postnatal cognitive development.

\section{Comparison with other studies}

Our study adds to the growing literature showing an association between birth weight and cognition across the normal range of birth weight, ${ }^{1-3}$ but only one such study has shown that the association persists with age beyond childhood. ${ }^{2}$ Few studies compare the association for birth weight and social background. The stronger influence of social background shown here is consistent with findings from two Scottish studies and with a Swedish study of intrauterine growth retardation in term infants followed to age $5 .^{1921}$

Our study extends two strands of work from the late 1970s on developmental trajectories in the 1958 birth cohort. ${ }^{20223}$ A previous report estimated that a

\section{What is already known on this topic}

Weight at birth is associated with later cognitive development

This is maintained across the range of normal birth weights

\section{What this study adds}

Social class at birth and birth weight have independent effects on maths scores in childhood, but social class at birth explains more of the variation in the scores

The relation between maths scores and birth weight persists across birth weights after adjustment for gestational age, parental education, and other potential confounding factors

Trajectories of maths attainment diverge, with more affluent social groups increasing their relative advantage whereas the effect of birth weight remains constant over time

$1 \mathrm{~kg}$ increase in birth weight was associated with a 4 month increase in reading scores at 7 years; this estimate was little changed by adjustment for possible confounding factors. ${ }^{22}$ Those weighing less than $2 \mathrm{~kg}$ at birth had a 1.2 year lower reading age $(0.4 \mathrm{SD})$ than those over $4 \mathrm{~kg}$. ${ }^{22}$ The difference in maths $\mathrm{z}$ scores across the range of birth weights is of similar magnitude (table 2). The widening social gap in mean scores with increasing age has been documented previously for reading and maths, and the influence of social background on adult educational attainment has also been reported. ${ }^{23}{ }^{24}$ We bring together the effects of social class and birth weight on educational trajectories into adolescence.

Our results suggest a cumulative effect of prenatal (birth weight) and postnatal (social class) influences on cognitive development. Although some previous research suggests a modifying effect of the social environment on the association between birth weight and cognition, we found no such interactive effect. ${ }^{25}$ Both birth weight and class of origin seem to be determinants of cognitive growth and are therefore likely to influence peak cognitive function. However, it is uncertain whether these factors also influence the rate and timing of cognitive decline later in life. For instance, the association between birth weight and cognitive function at 43 years was weak in the 1946 birth cohort despite associations with cognition from ages 8 to $26,{ }^{2}$ whereas in a retrospective cohort of men and women in their $50 \mathrm{~s}$ and $60 \mathrm{~s}$, the relation between birth weight and cognitive function was weak and nonsignificant. ${ }^{11}$ However, social circumstances in childhood remained important determinants of cognitive function among Finnish adult men, even after allowing for adult social circumstances. ${ }^{26}$

Although the overall effect size of differences in cognitive scores associated with birth weight is small for individuals, the impact in populations may be important. The stronger influence of social factors on cognitive function through to adult life, however, suggests that gains in cognitive development depend 
more on efforts to redress disadvantages in a child's social environment.

We thank the Data Training School, Canadian Research Institute for Social Policy for its input to preliminary analyses and the following for data: Centre for Longitudinal Studies, Institute of Education, National Child Development Study Composite File, including selected perinatal data and sweeps one to five (computer file), National Birthday Trust Fund, National Children's Bureau, City University, Social Statistics Research Unit (original data producers), and the Data Archive distributor, Colchester, Essex. (SN: 3148. 1994.$)$

Contributors: BJMHJ, $\mathrm{CP}$, and $\mathrm{CH}$ contributed to the conception, design, analysis, and writing up of this study. BJMHP and $\mathrm{CP}$ will act as guarantors for the paper.

Funding: Canadian Institute for Advanced Research.

Competing interests: None declared.

1 Shenkin SD, Starr JM, Pattie A, Rush MA, Whalley LJ, Deary IJ. Birth weight and cognitive function at age 11 years: the Scottish Mental Survey 1932. Arch Dis Child 2001;85:189-96.

2 Richards M, Hardy R, Kuh D, Wadsworth ME. Birth weight and cognitive function in the British 1946 birth cohort: longitudinal population based study. BMJ 2001;322:199-203.

3 Sorensen HT, Sabroe S, Olsen J, Rothman KJ, Gillman MW, Fischer P. Birth weight and cognitive function in young adult life: historical cohort study. BMJ 1997;315:401-3

4 Matte TD, Bresnahan M, Begg MD, Susser E. Influence of variation in birth weight within normal range and within sibships on IQ at age 7 years: cohort study. BMJ 2001;323:310-4.

5 Strauss RS. Adult functional outcome of those born small for gestational age: twenty-six-year follow-up of the 1970 British birth cohort. JAMA 2000;283:625-32.

6 Pharoah PO, Stevenson CJ, Cooke RW, Stevenson RC. Clinical and subclinical deficits at 8 years in a geographically defined cohort of low birthweight infants. Arch Dis Child 1994;70:264-70.

7 The Scottish low birthweight study: I. Survival, growth, neuromotor and sensory impairment. Arch Dis Child 1992;67:675-81.

8 Ounsted MK, Moar VA, Scott A. Small-for-dates babies at the age of four years: health, handicap and developmental status. Early Hum Dev 1983:8:243-58.

9 Drillien CM. School disposal and performance for children of different birthweight born 1953-1960. Arch Dis Child 1969;44:562-70.
10 Seidman DS, Laor A, Gale R, Stevenson DK, Mashiach S, Danon YL. Birth weight and intellectual performance in late adolescence. Obste Gynecol 1992;79:543-6.

11 Martyn CN, Gale CR, Sayer AA, Fall C. Growth in utero and cognitive function in adult life: follow up study of people born between 1920 and 1943. BMJ 1996;312:1393-6.

12 Butler NR, Alberman E. Perinatal problems. The second report of the British perinatal mortality survey. Edinburgh and London: E and S Livingstone, 1969.

13 Ferri E, ed. Life at 33. The fifth follow-up of the national child development study. London: National Children's Bureau, 1993.

14 Goldstein $\mathrm{H}$. A study of the response rates of 16-year-olds in the national child development study. In: Fogelman KR, ed. Growing up in Great Britain. Papers from the national child development study. London and Basingstoke: Macmillan Press, 1983:9-18.

15 Southgate V. Southgate group reading tests: manual of instructions. London: University of London Press, 1962.

16 Goodenough FL. The measurement of intelligence by drawings. New York: World Book Company, 1926.

17 Douglas JWB. The home and the school. London: MacGibbon and Kee, 1964.

18 Goldstein H. Multilevel statistical models, 2nd ed. London: Institute of Education, 1995.

19 Power C, Li L. Cohort study of birthweight, mortality, and disability. BMJ 2000;320:840-1

20 Davie R, Butler NR, Goldstein H. From birth to seven (with full statistical appendix). A report of the national child development study. London: Longman, 1972.

21 Sommerfelt K, Andersson HW, Sonnander K, Ahlsten G, Ellertsen B, Markestad T, et al. Cognitive development of term small for gestational age children at five years of age. Arch Dis Child 2000;83:25-30.

22 Goldstein H, Peckham C. Birthweight, gestation, neonatal mortality and child development. In: Roberts DF, Thomson AM, eds. The biology of human fetal growth. London: Taylor and Francis, 1976:81-102.

23 Fogelman KR, Goldstein H, Essen J, Ghodsian M. Patterns of attainment. Educ Stud 1978;4:121-30.

24 Power C, Matthews S. Origins of health inequalities in a national population sample. Lancet 1997;350:1584-9.

25 Werner EE, Smith RS. A longitudinal study of perinatal risk. In: Farran DC, McCenney JD, eds. Risk in intellectual and psychosocial development. New York: Academic Press, 1986

26 Kaplan GA, Turrell G, Lynch JW, Everson SA, Helkala EL, Salonen JT. Childhood socioeconomic position and cognitive function in adulthood. Int J Epidemiol 2001;30:256-63.

(Accepted 7 March 2002) 